\title{
Identificação de Aspergillus spp. toxigênico em arroz
}

\author{
Identification of toxigenic Aspergillus spp. in rice \\ Ívina Catarina de Oliveira GUIMARÃES ${ }^{1}$, Adriana Régia Marques SOUZA², \\ Vanda Maria de Oliveira CORNÉLIO ${ }^{3}$, Joelma PEREIRA ${ }^{4 \star}$, Valéria Andrade VILLELA ${ }^{5}$
}

\section{Resumo}

A composição química e o modo de cultivo do arroz o tornam susceptível à contaminação fúngica e, consequentemente, por micotoxinas. Considerando-se o expressivo consumo de arroz e a possibilidade de ser potencial fonte de micotoxinas, especial atenção deve ser dispensada quanto à qualidade do produto adquirido. Assim, o presente trabalho teve como objetivo avaliar espécies do gênero Aspergillus quanto à capacidade toxigênica, em diferentes subgrupos de arroz. As amostras constituíram-se de 31 marcas de arroz referentes aos subgrupos branco polido (21) e parboilizado (10), mais comumente comercializadas na cidade de Lavras - MG. Ao contrário dos outros subgrupos, a incidência de Aspergillus flavus e Aspergillus niger em amostras de arroz branco polido aumentou significativamente após a desinfecção. Pôde-se observar que, 50\% dos Aspergillus flavus e 50\% dos Aspergillus niger encontrados, foram considerados toxigênicos para o subgrupo branco polido. $\mathrm{Na}$ amostra de arroz parboilizado, 67\% dos Aspergillus flavus eram potenciais produtores. O Aspergillus ochraceus não se revelou como toxigênico. Este estudo permitiu concluir que, apesar de trabalhos isolados, a presença de fungos toxigênicos em arroz é verídico, o que se torna relevante por se tratar de um cereal importante no cenário mundial.

Palavras-chave: fungos toxigênicos; micotoxinas; arroz.

\begin{abstract}
The chemical composition and its methods of cultivation, make rice plants susceptible to fungi and consequently to mycotoxins contamination. Considering the expressive rice consumption and given the possibility that it maybe a potential source of mycotoxins, special attention should be devoted to its quality. Thus, this study was carried out to evaluate the Aspergillus species as to its toxigenic capacities in different rice subgroups. Thirty one and rice brands among the most popular brands sold in the city of Lavras - MG, were collected as samples, (21) polished white and (10) parboiled, respectively. Unlike other subgroups, the incidence of Aspergillus flavus and Aspergillus niger in the samples of polished white rice increased significantly after disinfecting. It was observed that $50 \%$ of the Aspergillus flavus and $50 \%$ of the Aspergillus niger were considered toxigenic in the white and polished rice subgroup. In the sample of parboiled rice, $67 \%$ of the Aspergillus flavus were potential producers. The Aspergillus ochraceus was not toxigenic. This study showed that the toxigenic fungi are present in rice, and this fact is relevant due to the importance of this cereal worldwide.
\end{abstract}

Keywords: toxigenic fungi; mycotoxins; rice.

\section{Introdução}

A cultura do arroz é de fundamental importância em todo o mundo, sendo este cereal, alimento básico em inúmeros países. Muitos patógenos podem estar associados às sementes e grãos de arroz, prejudicando a qualidade sanitária das sementes que serão utilizadas para o plantio e influenciando a qualidade nutricional dos grãos utilizados na alimentação humana.

Lazzari (1997) relata que, dentre os patógenos mais comuns, destaca-se a contaminação fúngica, responsável por perdas na produtividade, valor nutricional e danos à saúde pública. Muita importância tem sido despendida aos fungos filamentosos, cujo produto secundário ao seu metabolismo, as micotoxinas, são responsáveis por efeitos deletérios à saúde humana. O desenvolvimento de fungos toxigênicos e a produção de micotoxinas dependem de um complexo conjunto de fatores. Os principais são a suscetibilidade do substrato, a colonização do fungo produtor, a temperatura e a umidade do substrato, a umidade relativa do ar durante o armazenamento e a capacidade biológica do fungo produzir micotoxinas (SCUSSEL, 2000).

Uma vez ingeridas, as micotoxinas causam diversos efeitos deletérios a saúde, induzindo diferentes sinais clínicos e lesões que são intimamente relacionados a cada micotoxina, dose ingerida, período de incubação e espécie animal envolvida (DILKIN; MALLMANN, 2006).

APHA (2001) cita os gêneros Aspergillus spp., Penicillium spp. e Fusarium spp. como os mais frequentemente associados com micotoxinas que ocorrem naturalmente em cereais, grãos e

${ }^{1}$ Nutrição/PIBIC, Fundação de Amparo à Pesquisa do Estado de Minas Gerais - FAPEMIG, Empresa de Pesquisa Agropecuária de Minas Gerais - EPAMIG, Lavras - MG,

E-mail: ivinagui@gmail.com

2 Centro de Energia Nuclear na Agricultura - CENA, Universidade de São Paulo - USP, E-mail: acornel@cena.usp.br

${ }^{3}$ Empresa de Pesquisa Agropecuária de Minas Gerais - EPAMIG, MG, E-mail: vanda.cornelio@epamig.ufla.br

${ }^{4}$ Universidade Federal de Lavras - UFLA, Lavras - MG, E-mail: joper@ufla.br

${ }_{5}^{5}$ Centro Universitário de Lavras - UNILAVRAS, Lavras-MG, E-mail:valeria@unilavras.edu.br

* A quem a correspondência deve ser enviada 
sementes em níveis que tornam os alimentos impróprios para o consumo.

A presença de fungos toxigênicos em alimentos não confirma a presença de micotoxinas, mas sim a possibilidade de contaminação. Por outro lado, a ausência destes fungos não garante que o alimento esteja livre destes compostos, pois estas toxinas persistem por um longo tempo, após o fungo ter perdido sua viabilidade (YOSHISAWA, 2001).

Considerando-se a elevada frequência de consumo de arroz e este ser fonte potencial de micotoxinas, especial atenção deve ser dispensada quanto à qualidade do produto adquirido. Assim, o presente trabalho teve como objetivo avaliar espécies do gênero Aspergillus quanto à capacidade toxigênica, em diferentes subgrupos de arroz.

\section{Material e métodos}

As amostras constituíram-se de 31 marcas de arroz referentes aos subgrupos branco polido (21) e parboilizado (10), mais comumente comercializadas na cidade de Lavras - MG. As análises foram conduzidas no Laboratório de Patologia de Sementes da UFLA e no Laboratório da EPAMIG/CTSM/ UFLA, em novembro de 2006. Para identificar as espécies de Aspergillus spp., seguiu-se metodologia descrita por Samson et al. (1995), analisando-se 400 grãos de arroz por amostra, sendo, 200 sem desinfestação e 200 com desinfestação. A desinfecção das amostras foi feita, utilizando-se solução de álcool 70\% e hipoclorito de sódio a 1,0\%, com sua imersão por um minuto e trinta segundos em cada solução e lavadas em água destilada autoclavada por três vezes. Posteriormente, os grãos de arroz foram semeados em placas de Petri, de $15 \mathrm{~cm}$ de diâmetro, contendo 3 papéis de filtro previamente esterilizados, umedecidos em água destilada esterilizada e acrescidos de $5 \mathrm{~mL}$ de Ágar Água 0,5\% por placa. Após o plaqueamento, as amostras foram levadas para a Câmara de Incubação $20^{\circ} \mathrm{C}$ com fotoperíodo 12:12 por sete dias. Após esse período, procedeu-se à identificação dos microrganismos presentes nas amostras com o auxílio de microscópio estereoscópico. Para a determinação das espécies potenciais produtoras de micotoxinas, utilizou-se a metodologia descrita por Lin e Dianese (1976), inoculando-se os isolados de Aspergillus flavus, Aspergillus ochraceus e Aspergillus niger, em Meio de Coco CAM (Cocunut-Agar-Medium), para posterior leitura no cromatovisor a $366 \mathrm{~nm}$.

\section{Resultados e discussão}

Observa-se na Tabela 1 que a incidência de Aspergillus flavus e Aspergillus niger em amostras de arroz branco polido aumentou significativamente após a desinfecção. Este fato pode ser associado à presença de trincas neste subgrupo, o que facilitou a penetração do fungo no interior do grão. A Organização das Nações Unidas para a Agricultura e a Alimentação (FAO, 2006) relata que o grão danificado tem mais tendência para invasão de fungos e, consequentemente, para contaminação de micotoxinas.

Nas amostras de arroz parboilizado (Tabela 2), constatase diferença significativa antes e após a desinfecção, com diminuição da contaminação por Aspergillus spp. após a
Tabela 1. Incidência de Aspergillus spp. em amostras de arroz do subgrupo branco polido, com desinfecção e sem desinfecção.

\begin{tabular}{llcc}
\hline \multicolumn{2}{c}{ Fungos } & $\begin{array}{c}\text { Sem } \\
\text { desinfecção }\end{array}$ & $\begin{array}{c}\text { Com } \\
\text { desinfecção }\end{array}$ \\
\hline Aspergillus flavus & Média & 37,38 & 42,81 \\
& Variância & 2122,35 & 1226,46 \\
Aspergillus niger & Média & 16,24 & 50,62 \\
& Variância & 142,29 & 9763,35 \\
Aspergillus ochraceus & Média & 1,90 & 0,09 \\
& Variância & 12,99 & 0,09 \\
\hline
\end{tabular}

Distribuição $t$ de Student a 5\% de probabilidade.

Tabela 2. Incidência de Aspergillus spp. em amostras de arroz do subgrupo parboilizado, com desinfecção e sem desinfecção.

\begin{tabular}{llcc}
\hline \multicolumn{2}{c}{ Fungos } & $\begin{array}{c}\text { Sem } \\
\text { desinfecção }\end{array}$ & $\begin{array}{c}\text { Com } \\
\text { desinfecção }\end{array}$ \\
\hline Aspergillus flavus & Média & 46,90 & 0,70 \\
& Variância & 1199,44 & 1,12 \\
Aspergillus niger & Média & 1,90 & 0,20 \\
& Variância & 3,87 & 0,17 \\
Aspergillus ochraceus & Média & 0,40 & 0,00 \\
& Variância & 0,26 & 0,00 \\
\hline
\end{tabular}

Distribuição de $t$ Student a 5\% de probabilidade

sanitização. A legislação brasileira define a parboilização como sendo o processo hidrotérmico, no qual o arroz em casca é imerso em água potável com temperatura acima de $58{ }^{\circ} \mathrm{C}$, seguido de uma gelatinização parcial ou total do amido e secagem (BRASIL, 1988). Segundo Nitzke (2004), as condições de temperatura, o tempo e a umidade deste processo garantem a estabilidade enzimática e a pasteurização sanitária. Assim sendo, o arroz parboilizado tende a sair do processamento no engenho com menor carga microbiológica.

$\mathrm{O}$ arroz, além de ser um alimento presente praticamente todos os dias na alimentação do brasileiro, contribui como ingrediente em vários produtos alimentícios - como cereais matinais, farinhas, bebidas, amido de arroz e alimentos infantis , e está aliado à alimentação em hospitais, creches, escolas entre outras. Pela grande participação do arroz na alimentação brasileira, a presença de micotoxinas, se houver, pode causar sérios problemas à saúde.

Em condições apropriadas, de acordo com dados da Organização das Nações Unidas para a Agricultura e a Alimentação (FAO, 2006), Aspergillus spp. cresce no amendoim, milho e em outros grãos, podendo produzir aflatoxinas, compostos identificados pela Agência Internacional de Pesquisa de Câncer como poderoso carcinogênico.

Mais de 20 espécies de Aspergillus produzem micotoxinas, sendo as mais comuns as da divisão flavi, que incluem três espécies: A.flavus, A. parasiticus, A. nomius (SALEEMULLAH et al., 2006). Em estudo realizado por Nunes et al. (2003), verificou-se a ocorrência de micotoxinas em 56 amostras de arroz para o 
consumo humano, entre os gêneros mais frequentes destaca-se o Aspergillus.

Na identificação de potencial toxigênico de Aspergillus spp, pôde-se observar que $50 \%$ dos Aspergillus flavus e $50 \%$ dos Aspergillus niger encontrados, foram considerados toxigênicos para o subgrupo branco polido. Na amostra de arroz parboilizado, estes fungos de caráter toxigênico também foram expressivos, com destaque para o Aspergillus flavus (67\%). O Aspergillus ochraceus não se revelou como toxigênico.

O Aspergillus niger é uma das poucas espécies de fungos que receberam o status de GRAS (Generally Regarded As Safe) conferido pela Food and Drug Administration (FDA) devido à sua baixa toxicidade, sendo que alguns isolados desse fungo produzem ocratoxina apenas em baixas quantidades (VARGA et al., 1996).

\section{Conclusões}

Este estudo permitiu concluir que, apesar de trabalhos isolados, a presença de fungos toxigênicos em arroz é verídica, o que se torna relevante por se tratar de um cereal importante no cenário mundial e que técnicas para detecção e eliminação das micotoxinas devem ser implementadas para a redução desse número e maior segurança dos consumidores.

\section{Agradecimentos}

À EPAMIG/FAPEMIG pela concessão de bolsa de Iniciação Científica e aos funcionários da EPAMIG pelo auxílio na condução da pesquisa.

\section{Referências bibliográficas}

AMERICAN PUBLIC HEALTH ASSOCIATION - APHA. Compendium of methods for the microbiological examination of foods. 4 ed. Washington, 2001. 676 p.
BRASIL. Ministério da Agricultura. Normas de identidade, qualidade, embalagem e apresentação do arroz. Brasília, 1988. p. 1-25. (v. 8, n. 20).

DILKIN, P., MALLMANN, C. A. Sinais clínicos e lesões causadas por micotoxinas. In: ENCONTRO NACIONAL DE MICOTOXINAS, 11, 2004. Anais... Piracicaba - SP: Escola Superior de Agricultura Luiz de Queiroz, Universidade de São Paulo. Disponível em: <http// www.lamic.ufsm.br>. Acesso em: 20 set. 2006.

FOOD AND AGRICULTURE ORGANIZATION - FAO. Rice around the world. 2006. Disponivel em: <http://www.fao.org/rice2004>. Acesso em: 02 jul. 2006.

LAZZARI, F. A. Umidade, fungos e micotoxinas na qualidade de sementes, grãos e rações. 2 ed. Curitiba: Ed. do Autor, 1997. $148 \mathrm{p}$.

LIN, M. T.; DIANESE, J. C. A coconut-agar medium for rapid detection of aflatoxin production by Aspergillus spp. Phytopathology, v. 66, n. 12, p. 1466-1469, 1976.

NITZKE, J. A. Terra de arroz. Rio Grande do Sul: UFRGS, 2004. Disponível em: $<$ http://www.ufrgs.br/icta/agronom/arroz/esqarroz. htm>. Acesso em: 08 dez. 2004.

NUNES, I. L. et al. Arroz comercializado na região sul do Brasil: aspectos micotoxicológicos e microscópicos. Ciência e Tecnologia de Alimentos, v. 23, n. 2, p. 190-194, 2003.

SALEEMULLAH, A. I. et al. Aflatoxin contents of stored and artificially inoculated cereals and nuts. Food Chemistry, v. 98, n. 4, p. 699-703, 2006.

SAMSON, R. A. et al. Introduction to foodborne fungi. 4 ed. Baam: Centraalbureau voor Schimmelcultures, 1995. $332 \mathrm{p}$.

SCUSSEL, V. M. Atualidades em micotoxinas e armazenagem de grãos. Florianópolis: Insular, 2000. 382 p.

VARGA, J. et al. Ochratoxin production by Aspergillus species. Applied and Environmental Microbiology, v. 62, n. 12, p. 4461-4464, 1996.

YOSHISAWA, T. Mycotoxins analyses for federative republic of Brazil. Japão: Trainig Course, 2001. 283 p. 